$\xi=$

\title{
Prevalence of infectious and non-infectious diseases in cattle population in Chittagong district of Bangladesh
}

\author{
A. T. M. Badruzzaman ${ }^{1}$, Md. Saiful Islam Siddiqui ${ }^{1}$, Md. Omer Faruk ${ }^{2}$, Nasrin Sultana Lucky ${ }^{1}$, \\ Mohammad Ali Zinnah ${ }^{3}$, Ferdaus Mohd. Altaf Hossain ${ }^{1}$, Md. Masudur Rahman ${ }^{1 *}$ \\ ${ }^{1}$ Faculty of Veterinary and Animal Science, Sylhet Agricultural University, Sylhet 3100, Bangladesh \\ ${ }^{2}$ Veterinary Surgeon, Hathazari Veterinary Hospital, Hathazari, Chittagong, Bangladesh \\ ${ }^{3}$ Department of Microbiology and Public Health, Bangabandhu Sheikh Mujibur Rahman Agricultural University, Gazipur, Bangladesh \\ *Corresponding author E-mail: rahmanmm.dpp@sau.ac.bd
}

\begin{abstract}
Background: Cattle are affected by many infectious and noninfectious diseases that can lead to economic losses to the farmers in terms of reduced growth and production performance and mortality.

Objectives: This study was conducted to investigate the prevalence of infectious and noninfectious diseases of cattle in Chittagong district of Bangladesh.

Methods: A total of 2614 clinical cases were diagnosed at five different veterinary hospitals in Chittagong district of Bangladesh during the year 2013. Disease diagnosis was made on the basis of owner's statement, general examination, clinical signs, gross pathology, and laboratory procedures. Data were analyzed to determine disease prevalence in cattle with respect to breed, sex and season.

Results: Diagnosed diseases were categorized as infectious diseases, parasitic diseases, digestive disorders, metabolic diseases, respiratory diseases and other diseases. According to our results, the prevalence of digestive disorders was the highest (45.14\%) followed by parasitic diseases (30.64\%), infectious diseases $(9.49 \%)$, respiratory diseases (3.90\%), metabolic diseases $(3.18 \%)$ and other diseases $(3.18 \%)$. Disease prevalence was highest in Cross-bred cattle (44. 23\%) followed by Red Chittagong cattle (28.46\%) and Non-descript Deshi $(27.31 \%)$. Female were more susceptible to diseases $(54.32 \%)$ than male cattle (45.68\%). Disease prevalence varied according to seasons. Highest prevalence was recorded in summer season $(37.49 \%)$ followed by rainy season $(34.81 \%)$ and winter season $(27.70 \%)$.

Conclusions: Our large set of data on cattle disease prevalence in Chittagong district of Bangladesh provides valuable insight to design and implement priority based research on specific disease and to take efficient control strategies against the diseases.
\end{abstract}

Keywords: Bangladesh; Cattle; Infectious Disease; Non-Infectious Disease; Prevalence.

\section{Introduction}

Bangladesh is an over populated, rural and agrarian country in the world. Cattle are very important component of the mixed farming system practiced in Bangladesh from long time. In Bangladesh, similar to high population density, livestock population is also high and near about $80 \%$ of population is employed in agriculture and livestock farming (BBS, 2008). Livestock is a vital component of rural economy in Bangladesh and is performing multifarious functions such as provisions of food, draft power and transport. Bangladesh earns foreign currency by exporting several byproducts such as hides, skin, bone etc and now biogas is also producing from cattle dung. The contribution of livestock in the magnitude of Gross Domestic Product (GDP) is about $16.23 \%$ in Bangladesh (BBS, 2008).

There are about 22.53 million cattle and 14.69 million goat population in Bangladesh (DLS, 2009). However, most of the animals are weak and emaciated with non-satisfactory productive performance due to malnutrition and diseases. Among the various constrains in the development of cattle, both infectious and noninfectious diseases are the most important limiting factors that cause significant mortality of adult cattle and neonatal calves each year (Debnath et al. 1990, Debnath et al. 1995). It was reported that variation in different cattle breed, their sex and environmental factors greatly influence the disease prevalence in livestock animals including cattle (Alim et al. 2011, Sarker et al. 2011, and Islam et al. 2014).

The present study was undertaken to investigate the prevalence of cattle diseases considering breed, sex and seasons at five different locations of Chittagong division in Bangladesh. The results of the current study will provide an overall idea about the distribution of diseases of cattle in the region which may assist researchers or clinicians to design and implement priority based research on specific disease and to take efficient control strategies against the diseases.

\section{Methods}

\subsection{Study area and study period}

This study was undertaken at five different Veterinary Hospitals located at five different Upazila (sub-district) under Chittagong district of Bangladesh namely Chittagong Veterinary and Animal Science University Satellite Clinic at Potia Upazila; Veterinary Hospital at Sadar Upazila; Veterinary Hospital at Hathajari Upazila; Community Based Veterinary Clinic at Sithakundo Upazila; Veterinary Hospital at Mirsorai Upazila. A total of 2614 clinical cases of cattle of different breed and sex were diagnosed 
during the period from January to December, 2013. The handling of animals in the study was performed in accordance with current Bangladesh legislation (Cruelty to Animals Act 1920, Act No. I of 1920 of the Government of the People's Republic of Bangladesh).

\subsection{Diagnosis of diseases}

Diagnosis of diseases was made by general physical examination of animals, clinical signs, gross pathology and laboratory procedures. During general physical examination animal's body condition, behavior, posture, gait, locomotive disturbance, pulse, respiration, temperature, abdominal distension, defecation etc were observed and/or recorded. Examination of different parts and systems of the body of sick animals were performed by using the procedure of palpation, percussion, auscultation, needle puncture and walking of animals. Owner's complaints were taken into account while performing general physical examination of a sick animal. Animal's breed, sex, age etc were also recorded in registered book. Specific bacterial, viral, and fungal diseases were diagnosed on the basis of specific clinical signs and gross lesions (Jones et al. 1996, Khan 2000). In some cases, confirmatory diagnosis were made by cultural and biochemical characteristics of causative organisms following standard procedure. Parasitic infestations were diagnosed by faeces examination under microscope as described previously (Soulsby 1986). Blood smears were prepared and examined under microscope after Giemsa's staining according to the methods described elsewhere (Hendrix \& Robinson, 2006) to confirm hemoprotozoan infestation.
Diagnosed diseases were categorized as infectious disease, parasitic disease, digestive disorder, respiratory disease, metabolic disease and other diseases for statistical analysis. Obtained data were analyzed by using statistical software 'STATA/IC-11.0' where descriptive statistics was expressed as proportion with $95 \%$ confidence interval (CI). For Chi-square test, results were expressed in percentage with $\mathrm{P}$-value and significance was determined when $\mathrm{P}<0.05$. The influences of cattle breed, sex and season on the prevalence of diseases were also analyzed.

\section{Results}

A total of 2614 clinical cases were diagnosed and the diseases were categorized as infectious disease, parasitic disease, digestive disorder, respiratory disease, metabolic disease and other disease. As shown in Table 1, the highest prevalence was recorded for digestive disorders $(45.14 \%)$ and the lowest prevalence was recorded for metabolic diseases (3.18\%). Prevalence of digestive disorders $(45.14 \%)$ and parasitic diseases $(30.64 \%)$ were significantly higher among six categories $(\mathrm{p}<0.01)$. Disease prevalence in Cross-bred cattle $(44.23 \%)$ was significantly higher $(\mathrm{p}<0.01)$ than that of Red Chittagong cattle $(28.46 \%)$ and Non-descriptive Deshi $(27.31 \%)$ and females were more susceptible to diseases than male cattle $(p<0.05)$ (Table 2$)$. Significantly higher prevalence of diseases $(\mathrm{p}<0.05)$ were recorded in summer season $(37.49 \%)$ than in rainy season $(34.81 \%)$ and winter season (27.70\%) (Table 3).

\subsection{Data analysis}

Table 1: Prevalence of Diseases in Cattle during the Year 2013 in Chittagong District of Bangladesh

\begin{tabular}{|c|c|c|c|c|}
\hline Disease category & Name of disease & No. of identified cases & Prevalence $(\%)$ & Prevalence $(\%)$ by category \\
\hline \multirow{11}{*}{ Infectious disease } & Anthrax & 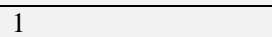 & 0.04 & $9.49(248)^{8}$ \\
\hline & Hemorrhagic septicemia & 7 & 0.27 & \\
\hline & Tetanus & 2 & 0.08 & \\
\hline & Foot rot & 9 & 0.34 & \\
\hline & Mastitis & 34 & 1.30 & \\
\hline & Arthritis & 19 & 0.73 & \\
\hline & Foot and mouth disease & 124 & 4.74 & \\
\hline & Ephemeral fever & 7 & 0.27 & \\
\hline & Wart & 37 & 1.41 & \\
\hline & Rabies & 3 & 0.12 & \\
\hline & Dermatophilosis & 5 & 0.19 & \\
\hline \multirow{9}{*}{ Parasitic disease } & Babesiosis & 21 & 0.80 & $30.64(801)^{* *}$ \\
\hline & Anaplasmosis & 5 & 0.19 & \\
\hline & Coccidiosis & 12 & 0.46 & \\
\hline & Balantidiasis & 7 & 0.27 & \\
\hline & Fascioliasis & 273 & 10.44 & \\
\hline & Paramphistomiasis & 159 & 6.08 & \\
\hline & Hump sore & 69 & 2.64 & \\
\hline & Strongyloidiasis & 43 & 1.65 & \\
\hline & Myiasis & 212 & 8.11 & \\
\hline \multirow[t]{4}{*}{ Digestive disorder } & Ruminal acidosis & 320 & 12.24 & $45.14(1180)^{* *}$ \\
\hline & Anorexia & 368 & 14.08 & \\
\hline & Simple indigestion & 418 & 15.99 & \\
\hline & Ruminal alkalosis & 74 & 2.83 & \\
\hline \multirow[t]{3}{*}{ Metabolic disease } & Milk fever & 33 & 1.26 & $3.18(83)$ \\
\hline & Grass tetany & 23 & 0.88 & \\
\hline & Weak calf syndrome & 27 & 1.03 & \\
\hline \multirow[t]{2}{*}{ Respiratory disease } & Aspiration pneumonia & 68 & 2.60 & $3.90(102)$ \\
\hline & Upper respiratory tract infestation & 34 & 1.30 & \\
\hline \multirow[t]{4}{*}{ Others } & Skin disease & 42 & 1.61 & $7.65(200)$ \\
\hline & Surgical affection & 120 & 4.59 & \\
\hline & Reproductive & 21 & 0.80 & \\
\hline & Congenital & 17 & 0.65 & \\
\hline Total & & 2614 & 100 & $100(2614)$ \\
\hline
\end{tabular}

$\S$ Values in the parenthesis indicate number of identified cases in each category; ** Significant at $\mathrm{p}<0.01$ by Chi-square test. 
Table 2: Prevalence of Diseases in Cattle with respect to Breed and Sex during the Year 2013 in Chittagong District of Bangladesh

\begin{tabular}{lllll}
\hline $\begin{array}{l}\text { Disease category } \\
(\mathrm{n}=2614)\end{array}$ & $\begin{array}{l}\text { Breed } \\
\text { Non-descript Deshi }\end{array}$ & Red Chittagong cattle & Cross-bred & $\begin{array}{l}\text { Sex } \\
\text { Male }\end{array}$ \\
\hline Infectious disease & $1.19(31)^{\S}$ & $2.52(66)$ & $5.78(151)$ & $4.36(114)$ \\
Parasitic disease & $9.41(246)$ & $9.03(236)$ & $12.06(319)$ & $10.75(281)$ \\
Digestive disorder & $12.7(332)$ & $12.36(323)$ & $20.09(525)$ & $23.41(612)$ \\
Metabolic disease & $1.03(27)$ & $0.76(20)$ & $1.38(36)$ & $21.73(568)$ \\
Respiratory disease & $1.11(29)$ & $1.34(35)$ & $1.46(38)$ & $0.35(9)$ \\
Others & $1.87(49)$ & $2.45(64)$ & $3.33(87)$ & $2.72(71)$ \\
Total & $27.31(714)$ & $28.46(744)$ & $44.23(1156)^{* *}$ & $4.09(107)$ \\
\hline
\end{tabular}

$\S$ Values in the parenthesis indicate number of identified cases and values outside the parenthesis indicate percent prevalence in each category; $*$ Significant at $\mathrm{p}<0.05$ by Chi-square test; $* *$ Significant at $\mathrm{p}<0.01$ by Chi-square test.

Table 3: Seasonal Prevalence of Diseases in Cattle during the Year 2013 in Chittagong District of Bangladesh

\begin{tabular}{|c|c|c|c|c|c|c|}
\hline $\begin{array}{l}\text { Disease category } \\
(n=2614)\end{array}$ & $\begin{array}{l}\text { Summer } \\
\text { No. of cases }\end{array}$ & Prevalence (\%) & $\begin{array}{l}\text { Rainy } \\
\text { No. of cases }\end{array}$ & Prevalence $(\%)$ & $\begin{array}{l}\text { Winter } \\
\text { No. of cases }\end{array}$ & Prevalence $(\%)$ \\
\hline Infectious disease & 78 & 2.98 & 94 & 3.60 & 76 & 2.91 \\
\hline Parasitic disease & 334 & 12.78 & 256 & 9.79 & 211 & 8.07 \\
\hline Digestive disorder & 468 & 17.90 & 431 & 16.49 & 281 & 10.75 \\
\hline Metabolic disease & 14 & 0.54 & 35 & 1.39 & 34 & 1.30 \\
\hline Respiratory disease & 20 & 0.76 & 30 & 1.15 & 52 & 1.99 \\
\hline Others & 66 & 2.52 & 64 & 2.45 & 70 & 2.68 \\
\hline Total & 980 & $37.49 *$ & 910 & 34.81 & 724 & 27.70 \\
\hline
\end{tabular}

*Significant at $\mathrm{p}<0.05$ by Chi-square test.

Overall prevalence of infectious diseases among six categories was $9.49 \%$ which constituted foot and mouth disease $(4.74 \%)$, wart $(1.41 \%)$, mastitis $(1.30 \%)$, arthritis $(0.73 \%)$, foot rot $(0.34 \%)$, ephemeral fever $(0.27 \%)$, hemorrhagic septicemia $(0.27 \%)$, dermatophilosis $(0.19 \%)$, rabies $(0.12 \%)$, tetanus $(0.08 \%)$ and anthrax (0.04\%) (Table1). The prevalence of infectious diseases was highest in Cross-bred cattle $(5.78 \%)$ and lowest in Nondescriptive Deshi (1.19\%) (Table 2). Females (5.13) were more susceptible to infectious diseases than male cattle $(4.36 \%)$ (Table 2 ) and the prevalence in summer, rainy and winter seasons were $2.98 \%, 3.60 \%$ and $2.91 \%$ respectively (Table 3 )

In parasitic disease category, nine parasitic diseases were identified of which five were gastrointestinal parasitic diseases and four were protozoan diseases (Table 1). Major parasitic diseases constituted fascioliasis $(10.44 \%)$, myiasis $(8.11 \%)$, paramphistomiasis $(6.08 \%)$, hump sore $(2.64 \%)$, strongyloidiasis $(1.65 \%)$, babesiosis $(0.80 \%)$, coccidiosis $(0.46 \%)$, balantidiasis $(0.27 \%)$, and anaplasmosis $(0.19 \%)$ (Table 1$)$. As in infectious disease category, Cross-bred female cattle were more susceptible to parasitic diseases (Table 2) and the prevalence in summer, rainy and winter seasons were $12.78 \%, 9.79 \%$ and $8.07 \%$ respectively (Table 3 ).

Highest prevalence $(45.14 \%)$ was recorded in digestive disease category of which simple indigestion was $15.99 \%$ followed by anorexia (14.08\%), ruminal acidosis (12.24\%), ruminal alkalosis $(2.83 \%)$ (Table1). Considering breed, sex and season, prevalence of digestive disorders were recorded as $20.09 \%$ in Cross-breed; $12.36 \%$ in Red Chittagong cattle; $12.7 \%$ in Non-descriptive Deshi; $23.41 \%$ in male; $21.73 \%$ in female; $17.90 \%$ in summer; $16.49 \%$ in rainy and $10.75 \%$ in winter (Table $2 \& 3$ ).

The overall prevalence of metabolic diseases was $3.18 \%$ of which milk fever constituted $1.26 \%$; weak calf syndrome $1.03 \%$ and grass tetany $0.88 \%$ (Table 1). Considering breed, sex and season, prevalence of metabolic diseases were recorded as $1.38 \%$ in Cross-breed; $0.76 \%$ in Red Chittagong cattle; $1.03 \%$ in Nondescriptive Deshi; $0.35 \%$ in male; $2.83 \%$ in female; $0.54 \%$ in summer; $1.39 \%$ in rainy and $1.30 \%$ in winter (Table $2 \& 3$ ).

The prevalence of respiratory diseases was recorded as $3.90 \%$ of which aspiration pneumonia was $2.60 \%$ and upper respiratory tract infection was $1.30 \%$ (Table 1). Considering breed, sex and season, prevalence of respiratory diseases were recorded as $1.46 \%$ in Cross-breed; $1.34 \%$ in Red Chittagong cattle; $1.11 \%$ in Nondescriptive Deshi; $2.72 \%$ in male; $1.18 \%$ in female; $0.76 \%$ in summer; $1.15 \%$ in rainy and $1.99 \%$ in winter (Table $2 \& 3$ ). In other diseases category, surgical affection, skin diseases, reproductive cases and congenital cases were included and the prevalence were recorded as $4.59 \%, 1.61 \%, 0.80 \%$, and $0.65 \%$ respectively (Table 1).

\section{Discussion}

To investigate the prevalence of cattle diseases at Chittagong division of Bangladesh, a total of 2614 clinical cases were diagnosed in six categories among which the prevalence of digestive disorders $(45.14 \%)$ and parasitic diseases $(30.64 \%)$ were significantly higher $(\mathrm{p}<0.01)$. Our results are in agreement with Pallab et al. (2012) who reported digestive disorders as $47.05 \%$ and parasitic infestation as $26.79 \%$ among other diseases in cattle. We found comparatively lower disease prevalence in local breed $(28.46 \%$ in Reg Chittagong and $27.31 \%$ in Non-descriptive Deshi) than in cross-bred cattle $(44.23 \%)$ which might be due to their natural resistance to diseases especially under rural production systems (Bhuiyan 2007, Mannan et al. 2009).

Overall prevalence of infectious diseases among six categories was $9.49 \%$ of which foot and mouth disease was recorded as $4.74 \%$. Sarker et al (2011) reported higher prevalence of foot and mouth disease (25.07\%) in Rajshahi district of Bangladesh. This variation might be due to different geographical locations and related environmental factors. In our study the prevalence of mastitis was $1.30 \%$ which is slightly lower than the report of Rahman et al (1972) and Pallab et al (2012). The prevalence of infectious diseases was highest in Cross-bred cattle $(5.78 \%)$ and lowest in Non-descriptive Deshi (1.19\%). Females were more susceptible to infectious diseases than male cattle. Our results are in agreement with the findings of Bhuiyan (2007) and Mannan et al (2009).

In parasitic disease category, fascioliasis was recorded as $10.44 \%$ and among hemoprotozoan parasites, prevalence of babesiosis and anaplasmosis were $0.80 \%$ and $0.19 \%$ respectively. Alim et al (2012) reported the overall prevalence of hemoprotozoan diseases as 16.18 and $12.02 \%$ in crossbred and indigenous cattle, respectively where babesiosis and anaplasmosis were predominant. Islam et al (2014) reported that prevalence of fascioliasis in house hold and slaughtered goats were $31.75 \%$ and $10.10 \%$ respectively. Variations in parasitic disease prevalence might be due to environmental factors, animal species and other related factors.

Highest prevalence $(45.14 \%)$ was recorded in digestive disease category of which simple indigestion was $15.990 \%$ followed by anorexia $(14.07 \%)$, ruminal acidosis $(12.24 \%)$, ruminal alkalosis (2.83\%). The prevalence of digestive disorders in our study was slightly lower than the report by Pallab et al (2012) and higher than the report by Rahman et al (1972) and Kabir et al (2010). In Bangladesh, most farmers are rearing cattle for fattening purpose and they are trying to feed their cattle excessively to make their cattle fatten within short period which might be the cause of highest prevalence of digestive disorders.

Overall prevalence of metabolic diseases $(3.18 \%)$ in our study was lower than the report by Pallab et al (2012) who reported metabol- 
ic disease prevalence as $4.24 \%$. Among the metabolic diseases, prevalence of milk fever was comparatively high which might be due to deficiency of calcium at the time of early lactation period. The prevalence of respiratory diseases was recorded as $3.90 \%$ which was lower than the report by Pallab et al (2012) who reported $6.20 \%$ prevalence.

\section{Conclusion}

According to our study, major diseases of cattle in Chittagong district of Bangladesh include digestive disorder, parasitic disease, infectious disease, respiratory disease and metabolic disease of which digestive disorders and parasitic diseases are predominantly prevalent diseases. Cross-bred female cattle are highly susceptible to most of the diseases. Our large set of data on cattle disease prevalence in Chittagong district of Bangladesh provides valuable insight to design and implement priority based research on specific disease and to take efficient control strategies against the diseases.

\section{Acknowledgements}

This research work was partly financed by Sylhet Argicultural University Research System (SAURES), Sylhet, Bangladesh. Authors are thankful to Veterinary surgeons of Sadar Upazila Veterinary Hospital and Hathajari Upazila Veterinary Hospital Veterinary Consultant of Chittagong Veterinary and Animal Science University Satellite Clinic at Potia Upazila, Community Based Veterinary Clinic at Sithakundo and Mirsorai Upazila for their co-operation to conduct the research.

\section{References}

[1] Alim MA, Das S, Roy K, Masuduzzaman M, Sikder S, Hassan MM, Siddiki AZ \& Hossain MA (2012) Prevalence of hemoprotozoan diseases in cattle population of Chittagong division, Bangladesh. Pakistan Veterinary Journal 32, 221-224.

[2] BBS (2008) Statistical year book on Bangladesh, Bangladesh Bureau Statistics, Ministry of Planning, and Dhaka.

[3] Bhuiyan AKFH (2007) Cattle and livelihood in Bangladesh. Available at: http://www.vishwagou.org/Cattle\%20and\%20Livelihood.htm (accessed 4 September 2014)

[4] DLS (2009) Annual Report of Directorate of Livestock Services (2008-2009), Bangladesh.

[5] Hendrix CM \& Robinson E (2006) Diagnostic Parasitology for Veterinary Technicians, Third editionn, Mosby Inc. and affiliated of Elsevier Inc, China, pp: 246-247.

[6] Islam KM, Rahman M, Islam MS, Adhikary GN \& Rauf SMA (2014) Epidemiological studies of fascioliasis (Fasciola gigantica) in black Bengal goats. Eurasian Journal of Veterinary Science 30, 152-156. http://dx.doi.org/10.15312/EurasianJVetSci.201436515.

[7] Jones TC, Hunt RD \& Kimg NW (1996) Veterinary Pathology, Sixth edition, Williams \& Wilkins, A Waverly Company, pp: 1024-1041.

[8] Kabir MH, Reza MA, Razi KMA, Parvez MM, Bag MAS \& Mahfuz SU (2010) A report on clinical prevalence of diseases and disorders in cattle and goat at the Upazilla Veterinary Hospital, Ulipur, Kurigram. International Journal of BioResearch 2, 17-23.

[9] Khan CM (2000) the Merck Veterinary Manual. Tenth edition, Merck Sharp \& Dohme Corporation. USA, pp: 501-524.

[10]Mannan MA, Siddique MP, Uddin MZ \& Parvaz MM (2009) Prevalence of foot and mouth disease (FMD) in cattle at Meghna upazila in Comilla in Bangladesh. Journal of the Bangladesh Agricultural University 7, 317-319.

[11]Pallab MS, Ullahb SM, Uddinc MM \& Miazic OF (2012) A cross sectional study of several diseases in cattle at Chandanaish Upazilla of Chittagong district. Scientific Journal of Veterinary Advances 1, 2832.

[12]Rahman MA, Ali KMKM \& Rahman A (1972) Incidence of diseases of cattle in Mymensingh. Bangladesh Veterinary Journal 6, 25-30.

[13] Sarker S, Talukder S, Haque MH, Islam MH \& Gupta SD (2011) Epidemiological study on foot and mouth disease in cattle: prevalence and risk factor assessment in Rajshahi, Bangladesh. Wayamba Journal of Animal Science 3, 71-73.
[14]Soulsby EJL (1986) Helminths, Arthropods and Protozoa of Domesticated Animals, Seventh edition, The ELBS and Baillier Tindall, London, UK, pp: 40-52. 